\title{
Electrochemical Liquid-Liquid-Solid Deposition of Crystalline Gallium Antimonide
}

Joshua DeMuth ${ }^{1}$, Luyao Ma ${ }^{1}$, Eli Fahrenkrug ${ }^{1}$ and Stephen Maldonado ${ }^{1,2 *}$

1) Department of Chemistry

2) Program in Applied Physics

University of Michigan

930 N. University

Ann Arbor, MI 48109-1055

\begin{abstract}
.
Direct electrodeposition of phase-pure crystalline gallium antimonide (GaSb) films has been achieved at low processing temperatures from an aqueous electrolyte. A liquid gallium electrode was used to drive the electroreduction of $\mathrm{Sb}_{2} \mathrm{O}_{3}$ dissolved in $0.6 \mathrm{M} \mathrm{NaOH}$. The quality and purity of the resultant films produced depended strongly on the chosen conditions, including temperature, time, and concentration of dissolved $\mathrm{Sb}_{2} \mathrm{O}_{3}$. Under select conditions, the direct production of polycrystalline films of GaSb was possible. Raman spectroscopy, powder X-ray diffraction, selected area electron diffraction, scanning electron microscopy, and transmission electron microscopy were separately used to analyze the identity and crystallinity of the electrodeposited films. The cumulative data showed that this electrodeposition process followed the features common both to conventional electrodeposition and melt crystal growth. Accordingly, this electrodeposition process could not be categorized as electrodeposition followed by annealing. Rather, the data implicate this method is akin to a hybrid electrodeposition solution-based crystal growth, where crystalline GaSb films could be grown up to thicknesses of $1 \mu \mathrm{m}$ in 60 min.

*smald@umich.edu
\end{abstract}

(C) 2015. This manuscript version is made available under the Elsevier user license http://www.elsevier.com/open-access/userlicense/1.0/ 


\section{Introduction}

Gallium antimonide (GaSb) thin films are attractive platforms for energy conversion technologies. For example, crystalline films of GaSb function as the absorber layers and /or substrate in the most efficient thermophotovoltaics [1-3], as deposition substrates for lattice matched ternary (AlGaSb, InAsSb) and quaternary (AlGaAsSb, InGaAsSb) alloys [4, 5], as infrared-capturing cells in tandem solar cells [6] and as the lasing medium in low voltage diode lasers [7]. Unfortunately, the current methods (e.g. metal organic chemical vapor deposition and molecular beam epitaxy) for the production of crystalline $\mathrm{GaSb}$ are problematic at scale in several ways. Specifically, they rely on toxic gaseous precursors, require costly instrumentation, and do not allow high throughput $[1,8]$. Accordingly, a need exists to find alternative methods for the preparation of crystalline GaSb that retain quality but are better suited for rapid mass production.

In principle, conventional electrodeposition is a potential low cost route for crystalline GaSb thin films when performed in aqueous electrolytes at/near room temperature. However, the extant literature shows several issues with conventional electrodeposition. Notably, electrodeposited GaSb is nonstoichiometric, amorphous, and contaminated with impurities from the electrolyte [9, 10]. These factors individually are problematic and collectively are detrimental for electronic and optoelectronic application [11, 12]. Non-stoichiometry is a direct consequence of unequal rates of incorporation of Ga and $\mathrm{Sb}$ in to the growing GaSb crystal. That is, the difference in the heterogeneous electroreduction rates of Ga- and Sb-containing precursors will lead to excesses/deficiencies of the constituent atoms in GaSb unless they are matched precisely. Further, electrodeposition of GaSb often results in films with high levels of impurities, both from the solvent and/or salts as well as metal contaminants in the electrolyte that were not removed prior to electrodeposition.

Alternatively, electrochemical liquid-liquid solid (ec-LLS) crystal growth is a new hybrid electrodeposition strategy amenable for the synthesis of crystalline semiconductor materials [13, 14]. Briefly, in ec-LLS a liquid metal working electrode is used that functions both as a source of electrons for heterogeneous reductions and as a separate solvent for semiconductor crystal nucleation and growth.[15] In effect, ec-LLS couples conventional electrodeposition with melt crystal growth by using a liquid metal electrode with the ability to solubilize GaSb as the solvent to mediate crystal growth. Finite equilibrium solubilities of both $\mathrm{Sb}^{0}(\mathrm{~s})$ and $\mathrm{GaSb}(\mathrm{s})$ in the liquid metal permits the formation of crystalline GaSb at low temperatures. Accordingly, this paper tests the hypothesis that an ec-LLS process can be developed for crystalline GaSb using liquid gallium electrodes and $\mathrm{Sb}_{2} \mathrm{O}_{3}$ dissolved in aqueous electrolyte. Figure 1 represents the ec-LLS tactic explored in this work. Through this method, we report the first demonstration 
of direct electrodeposition of crystalline GaSb at temperatures below the boiling point of water. Process conditions and experimental criteria for this method are identified and discussed herein.

\section{Experimental}

2.1 Materials. Antimony oxide $\left(\mathrm{Sb}_{2} \mathrm{O}_{3}, 99 \%\right.$ Aldrich), sodium hydroxide ( $\mathrm{NaOH},>97 \%$, Fisher), and Ga (99.999\%, Alfa Aesar) were used as received. Water with a resistivity $>18.2 \mathrm{M} \Omega \mathrm{cm}$ (Nanopure Barnstead Water Purification) was used throughout.

2.2 Electrochemical Experiments. CHI420A and CHI760C (CH Instruments) workstations and a Solartron 1286 (Solartron) potentiostat were used interchangeably for electrochemical experiments. All measurements were performed in a three-electrode Pyrex cell under ambient pressure. A liquid gallium pool housed within a glass bowl and contacted by a Pt wire that was isolated from the liquid electrolyte by a polytetrafluroethylene (PTFE) coating was used as the working electrode, Pt-mesh was used as the counter electrode, and a Pt-wire was employed as a quasi- reference electrode. All potentials were then converted to the $\mathrm{Ag} / \mathrm{AgCl}$ reference potential scale through the voltammetric response of the $\left[\mathrm{Fe}(\mathrm{CN})_{6}\right]^{3 / 4-}$ redox couple. Unless indicated otherwise, all potentials are reported relative to $\mathrm{E}(\mathrm{Ag} / \mathrm{AgCl} / \mathrm{Sat} . \mathrm{KCl}(\mathrm{aq}))$.

2.3 Materials Characterization. Raman spectra were taken using a Renishaw RM Series Raman microscope using a Nikon LU Plan 20x objective (NA = 0.4), with edge filters for the $785 \mathrm{~nm}$ excitation line, in a backscatter geometry. A $785 \mathrm{~nm}$ diode laser was used as the incident excitation source with a total radiant power of $1.12 \mathrm{~mW}$ over a $20 \mu^{2}$ spot which was collected for 20 seconds. The peak position of the TO mode for crystalline GaSb in the Raman spectra was obtained by fitting with a Voigt function using a max of 500 iterations with a tolerance of $10^{-15}$. Scanning electron micrographs were obtained from a FEI Nova Nanolab Dualbeam Focussed Ion Beam Workstation using a Schottky field emitter filament functioning at an acceleration voltage of $5 \mathrm{kV}$ and a beam current $0.54 \mathrm{nA}$ and a 1455 LEO scanning electron microscope using a tungsten filament source functioning at an acceleration voltage of $10 \mathrm{keV}$ and a beam current $20 \mathrm{pA}$. The secondary electrons were collected from an Everhart-Thornly Detector (ETD) or a through-the-lens detector (TLD). Powder X-Ray diffractogram were obtained from a Bruker D8 Advance X-ray diffractometer with a $\mathrm{Cu} \mathrm{K \alpha} \mathrm{X-ray} \mathrm{source}(\lambda=1.5406 \AA)$. The source slit was $0.6 \mathrm{~mm}$ using a data sampling interval of $0.040^{\circ}$ for 0.7 seconds at each interval. Dark field and bright field transmission electron micrographs as well as the selected area electron diffraction pattern were collected with a JEOL 3011 TEM using a $\mathrm{LaB}_{6}$ filament functioning at $300 \mathrm{kV}$. The TEM samples were prepared by freezing the liquid gallium $(\mathrm{Ga}(l))$ electrode directly after the deposition and removing the surface film with a razor blade. The razor blade was then placed in a scintillation vial containing about $1 \mathrm{~mL}$ of 
methanol (190 proof, ACS spectrophotometric grade, Aldrich) and sonicating the suspension for approximately 45-60 min. A droplet of about $30 \mu \mathrm{L}$ of the suspension was then casted onto a 400 mesh Cu TEM grid coated with an ultrathin carbon support (Ted Pella). The extensive sonication was needed due to the large particle size of the GaSb films. The SAED pattern for crystalline GaSb was simulated along the [111], space group F-43m, with the software Crystal Maker.

\section{Results}

Figure 2 shows the current-potential response at the $\mathrm{Ga}(l)$ electrode for electrolyte in the presence and absence of dissolved $\mathrm{Sb}_{2} \mathrm{O}_{3}$ at a series of different concentrations. The maximum formal concentration attainable in this electrolyte was $0.6 \mathrm{mM}$. At the electrolyte $\mathrm{pH}$ of 12.3 , the predominant species in solution is $\mathrm{Sb}(\mathrm{OH})_{4}{ }^{-} \cdot[16,17]$ In the blank electrolyte, the liquid gallium pool electrode readily oxidized at potentials less negative than $-1.2 \mathrm{~V}$ but was stable at more negative potentials. These liquid gallium pool electrodes showed poor electrocatalytic activity for the $\mathrm{H}^{+} / \mathrm{H}_{2}$ redox couple $\left(\log \left(J_{0} / \mathrm{mA} \mathrm{cm}^{-2}\right)\right.$ $\left.=-10.1, d \log (J) / d E=-6.1 \mathrm{~V}^{-1}\right)$. At this $\mathrm{pH}$, the standard potential for the reduction of $\mathrm{Sb}(\mathrm{OH})_{4}{ }^{-}$is -0.720 V.[16] Upon introducing $\mathrm{Sb}_{2} \mathrm{O}_{3}$ into solution, the cathodic current increased, indicating the liquid gallium electrode is active for the electroreduction of $\mathrm{Sb}(\mathrm{OH})_{4}{ }_{4}^{-}$. However, a cathodic wave indicative of a diffusional limit for the reduction of $\mathrm{Sb}(\mathrm{OH})_{4}{ }^{-}$was not cleanly observed. Prolonged chronoamperometric experiments at potentials $\leq-1.27 \mathrm{~V}$ resulted in the electrodeposition of a film. Figures $2 \mathrm{~b}$ and $2 \mathrm{c}$ show the $\mathrm{Ga}(l)$ pool electrode before and after being submerged in the $0.6 \mathrm{M} \mathrm{NaOH}$ electrolyte with an applied bias of $-1.47 \mathrm{~V}$ for $60 \mathrm{~min}$. After approximately 25 to 30 minutes, uniform films with a dark hue consistently appeared on the electrode surface under these conditions.

To ascertain the chemical identity of the films, Raman spectra were collected. Figure 3 shows Raman spectra of the films formed after electrodeposition for $60 \mathrm{~min}$ at $90{ }^{\circ} \mathrm{C}$ at different applied potentials. For experiments where the $\mathrm{Ga}(l)$ electrode was held at open circuit potential $(E=-1.23 \mathrm{~V})$, the Raman spectra showed two large features at about 115 and $149 \mathrm{~cm}^{-1}$, which is consistent with phonons for crystalline $\mathrm{Sb}^{0}$ ( $E_{g}$ and $A_{1 g}$, respectively).[18, 19] At potentials that induced a large net cathodic current, the corresponding Raman spectra of the film showed only a single peak at approximately $226 \mathrm{~cm}^{-1}$. This signature was inconsistent with any known mode for crystalline or amorphous $\mathrm{Sb}^{0}$. Rather, the data more closely agreed with an assignment of the transverse optical phonon mode of crystalline GaSb [20-23]. Nevertheless, there was no signal consistent with the longitudinal optical (LO) phonon mode. Unlike most other III-V semiconductors, the peak positions for the LO and TO phonons are closely spaced in the Raman spectra of crystalline GaSb (TO mode $~ 226 \mathrm{~cm}^{-1}$ and LO mode 232).[18, 22, 23] In polycrystalline GaSb samples, only one peak is typically resolved.[22] 
Generally, the peak positions of the optical phonon modes and the crystallite domain size are strongly correlated. However, earlier studies of the annealing of disordered GaSb films via Raman spectroscopy established that the spectral features do not directly report on crystal size as in other III-V semiconductors.[22] Specifically, although similar qualitative trends (blue shift of modes in Raman spectra and peak width narrowing) were observed with increasing crystallite size, the quantitative correlation of spectral features and the crystallite size (i.e. extent of phonon confinement) was poor.[22] Accordingly, attempts to estimate crystalline domain sizes from the collected Raman spectra were not performed here. Nevertheless, the peak position and linewidth of this signature in the Raman spectra collected did not change in experiments as a function of potential, implying a nominally constant crystallite size at different applied potentials.

The features in the collected Raman spectra were dependent on the formal concentration of $\mathrm{Sb}_{2} \mathrm{O}_{3}$ in the electrolyte. Figure 4 shows Raman spectra of electrodeposited films for a constant time $(t=60 \mathrm{~min})$ as a function of the formal $\mathrm{Sb}_{2} \mathrm{O}_{3}$ concentration over a range of $0.01-0.6 \mathrm{mM}$. The cumulative spectral features are collected in Table 1 . The peaks in the Raman spectra were integrated and analyzed using Origin software. From 0.1-0.6 mM, the absolute intensity of the TO phonon mode for GaSb decreased as the concentration of $\mathrm{Sb}_{2} \mathrm{O}_{3}$ increased. For concentrations of $0.2 \mathrm{mM}$ or higher, spectral features diagnostic of crystalline $\mathrm{Sb}^{0}$ were observed. At high concentrations, these features dominated the spectra. At low concentrations ( $\left.\left[\mathrm{Sb}_{2} \mathrm{O}_{3}\right] \leq 0.1 \mathrm{mM}\right)$, the spectra indicated a 'clean' electrodeposition product of crystalline GaSb, mirroring earlier observations in the electrodeposition of crystalline GaAs at liquid gallium pool electrodes.[15] Since the peak position of the GaSb TO mode in the Raman spectra does not significantly change as the concentration is varied from 0.01 to $0.4 \mathrm{mM}$, the crystallite size within GaSb films appeared insensitive to the formal concentration of dissolved $\mathrm{Sb}_{2} \mathrm{O}_{3}$.

Figure 5 presents Raman spectra of electrodeposited films as a function of the electrodeposition temperature. The lower bound on the investigated temperature range was $T=40{ }^{\circ} \mathrm{C}$ to ensure that the $\mathrm{Ga}$ was molten during the deposition $\left(T_{\text {melt }}=29.7^{\circ} \mathrm{C}\right.$ ) [24]. All spectra possessed a discernible signal (above the background) consistent with the TO phonon mode for crystalline GaSb. However, the spectra differed significantly in other aspects. First, both the intensity and the line width of the TO phonon mode was a strong function of temperature. Second, a broad mode between 110 and $175 \mathrm{~cm}^{-1}$ was evident at $T=40$ and $50{ }^{\circ} \mathrm{C}$ only. A similar feature in the Raman spectra of amorphous GaSb has been assigned as the longitudinal phonon mode.[19, 22] Accordingly, we interpret this feature as diagnostic of GaSb with extremely low order (high disorder). In spectra where this mode was present, the TO mode for GaSb was redshifted, consistent with the premise of small domains of ordered GaSb. Third, the intensity of this 'disorder' feature vanished in Raman spectra where the GaSb TO phonon mode shifted to higher 
frequencies (Figure 5b). A similar temperature dependence of Raman spectral features was reported previously in annealing studies of GaSb films.[22]

Two additional experiments were performed to ascertain whether the GaSb films electrodeposited (1) first as amorphous thick films that were then converted thermally to crystalline materials or (2) directly as crystalline films, i.e. they never were amorphous. First, a series of Raman spectra were obtained for electrodepositions performed at $E=-1.47 \mathrm{~V}$ at $T=90{ }^{\circ} \mathrm{C}$ at several durations (Figure 6). At the start of the experiment, there was no observable film on the electrode surface and no discernable Raman signal between 100 and $300 \mathrm{~cm}^{-1}$. After $0.5 \mathrm{~min}$, the background increased, with a broad profile spanning $100 \sim 250 \mathrm{~cm}^{-1}$. A small fraction of the surface began to show different Raman spectra. These areas showed a peak at $150 \mathrm{~cm}^{-1}$ while the phonon for GaSb appeared at $223.5 \mathrm{~cm}^{-1}$. Although acoustic phonon modes are not typically observed for crystalline GaSb due to selection rules,[25] GaSb has a longitudinal acoustic mode at $150 \mathrm{~cm}^{-1}$ which has been observed in GaSb with short range order.[19] Another peak at $179 \mathrm{~cm}^{-1}$ was observed but was not readily assignable. After $2 \mathrm{~min}$, the Raman spectra changed again and were more uniform across the electrode surface. The feature at $150 \mathrm{~cm}^{-1}$ disappeared. After 10 min the overall spectra remained essentially unchanged aside from a slight redshift in the TO mode of GaSb which now dominated the spectra. The measured Raman shift of the TO mode is consistent with that previously reported for crystalline GaSb ranging from 224 to $228 \mathrm{~cm}^{-1}$.[20, 22, 23, 25] Figure 5b shows the Raman shift in the TO mode as a function of the electrodeposition time. These data collectively imply that the GaSb crystallites were actively growing during the course of the entire ec-LLS experiment.

Second, a separate experiment was performed where GaSb films were electrodeposited at $T=40$ ${ }^{\circ} \mathrm{C}$ for $60 \mathrm{~min}$ and subsequently heated at $T=60{ }^{\circ} \mathrm{C}$ for $60 \mathrm{~min}$. The purpose of this experiment was to determine whether a GaSb film showing poor crystallinity could be 'annealed' in the blank electrolyte under potential control (to prevent oxide formation) to a more crystalline form and yield spectra equivalent to an ec-LLS performed at $T=60^{\circ} \mathrm{C}$. In this experiment, the broad signal between 110 and $175 \mathrm{~cm}^{-1}$ in the Raman spectra persisted (i.e. did not disappear) and the GaSb TO mode red shifted slightly. Both of these features were not observed in the Raman spectra of the films deposited by ec-LLS at $T=60^{\circ} \mathrm{C}$ and both observations actually imply a decrease in GaSb crystallite size. Accordingly, the data suggest that the materials produced by ec-LLS at a given temperature are not the same as those electrodeposited at lower temperatures and then subsequently annealed at the given temperature.

The morphology of the GaSb crystals produced by ec-LLS was assessed through electron microscopy. The microscopic structures of GaSb films prepared by ec-LLS lasting 60 min are shown in Figure 7. The electrodeposits were films with a thickness of $1.06 \mu \mathrm{m}+/-6 \%(N=25$ measurements from 
5 different regions). The films were contiguous but easily fractured into discrete, faceted particles as large as 4-5 $\mu \mathrm{m}$ in length and $8 \mu \mathrm{m}$ in width when mechanically moved. The films yielded an X-ray diffractogram that showed all of the expected signatures for crystalline GaSb (Figure 8). The relative intensities of the diffraction pattern were inconsistent with randomly oriented isotropic crystallites, even after correcting for the attenuation in the relative diffracted intensity observed for higher angle reflections in thin films using absorption factor.[26] Rather, the data suggested that there was a texture or a preferred orientation of the $\{111\}$ crystallographic planes normal to the surface plane of the Ga(l) electrodes. However, the non-flat form factor of the underlying liquid metal substrate limited quantitative assessment of anisotropy from the X-ray diffraction data. Nevertheless, the narrow peak width of the (111) signal suggests that the crystallites were larger than $0.2 \mu \mathrm{m}$ in at least that direction.

Transmission electron microscopy (TEM) and selected area electron diffraction (SAED) were employed to directly measure the crystallite grain size in films that had been removed from the liquid gallium electrode surface, sonicated, and then recast onto a TEM grid. The prolonged sonication used to prepare the TEM sample mechanically shattered the original crystallites. Figure 9a shows the observed SAED pattern along the [111] zone axis. The distance between the 000 and 2-20 diffracted beams was $0.467 \AA^{-1}$, corresponding to an interplanar spacing of $2.14 \AA$ between adjacent 2-20 crystallographic planes. The measured value is in good agreement with the interplanar spacing predicted in the SAED pattern simulated for crystalline GaSb (Figure 9b). Dark field (DF) transmission electron micrographs of the crystallite shown in the corresponding bright field (BF) transmission electron micrograph (Figure 9c and d, respectfully) showed the grain size of a section of the electrodeposited film. The DF image was obtained after selecting for the 2-20 diffracted beam and shows that the diffraction contrast from the 2-20 plane is observed throughout the crystallite with a projected domain size of about $0.2 \mu \mathrm{m} \times 0.1 \mu \mathrm{m}$. The non-uniform diffraction contrast in the DF TEM image was attributed to irregular crystallite thickness.[27]

\section{Discussion}

The cumulative data speak to three separate points. First, the direct electrodeposition of crystalline $\mathrm{GaSb}$ from an aqueous electrolyte at moderate temperatures is possible and reproducible. Second, the crystalline properties of electrodeposited GaSb are a complex function of several process variables. Third, the process has strong parallels to our earlier demonstration of the direct electrodeposition of crystalline GaAs through the electroreduction of $\mathrm{As}_{2} \mathrm{O}_{3}$ at liquid gallium electrodes.

4.1 Direct Formation of Crystalline GaSb A key aspect of this work is the spontaneous formation of GaSb when $\mathrm{Sb}^{0}$ is introduced onto/into liquid gallium. At room temperature, the $\Delta G_{\mathrm{f}}$ for the reaction 
between elemental Ga and $\mathrm{Sb}$ is between -51.9 and $-54.3 \mathrm{~kJ} \mathrm{~mol}^{-1}$.[28] That is, as long as $\mathrm{Ga}^{0}$ and $\mathrm{Sb}^{0}$ are in intimate contact, some amount of GaSb should be formed. A general premise in electrodeposition processes is that the size of the initial nucleus during an electrodeposition process is a strong function of both the overpotential of the electroreduction and the concentration of oxidized precursor in solution.[29] As pictorially diagrammed in Figure 10, our contention is that when electrodeposition is performed under conditions that favor a high density of Sb nuclei that quickly form large clusters, dissolution of $\mathrm{Sb}^{0}$ into $\mathrm{Ga}$ is impeded. Conversely, when the initial electrodeposition is performed under conditions encouraging the formation of small $\mathrm{Sb}^{0}$ nuclei that remain isolated, then the electrochemical potential gradient across the electrolyte/electrode interface is effective at driving $\mathrm{Sb}^{0}$ dissolution to the point of supersaturation. When the formal concentration of $\mathrm{Sb}_{2} \mathrm{O}_{3}$ is large, the issue with high densities of $\mathrm{Sb}^{0}$ accumulating at the electrode surface is apparently unavoidable. That is, crystalline $\mathrm{Sb}^{0}$ is the main product and GaSb is only formed sparingly. In dilute solutions of dissolved $\mathrm{Sb}_{2} \mathrm{O}_{3}, \mathrm{Sb}^{0}$ nuclei are discrete and readily dissolved into $\mathrm{Ga}$ and form $\mathrm{GaSb}$, apparently outpacing the rate of accumulation of discrete $\mathrm{Sb}^{0}$ nuclei into macroscopic clusters. At larger negative overpotentials, the heterogeneous reduction rate for the electrode reaction $\left[\mathrm{Sb}(\mathrm{OH})_{4}\right]^{-}(\mathrm{aq})+3 e^{-} \rightarrow \mathrm{Sb}^{0}(\mathrm{~s})+4 \mathrm{OH}^{-}(\mathrm{aq})$ increases and the interspacing between discrete nuclei will decrease on the electrode.[29, 30] Consequently, a more negative overpotential in a deposition would again be expected to favor the formation of $\mathrm{Sb}^{0}$ on the Ga electrode surface rather than GaSb. However, in experiments where the overpotential for electrodeposition was made more negative the expected result was not observed. Rather, as long as the applied potential was more negative than the open circuit potential, then crystalline GaSb was always favored over $\mathrm{Sb}^{0}$. In addition, we observed repeatedly that the formation of crystalline $\mathrm{Sb}^{0}$ was favored over GaSb at open circuit. We propose that the formation of crystalline $\mathrm{Sb}^{0}$ at open circuit was a result of a Galvanic displacement reaction between the $\mathrm{Sb}(\mathrm{OH})_{4}{ }^{-} / \mathrm{Sb}^{0}$ couple and the $\mathrm{Ga}^{0} / \mathrm{GaO}_{3}{ }^{3-}$ couple.[17] We speculate that under these conditions $\mathrm{Sb}^{0}$ forms grains too large to readily dissolve in liquid Ga, thereby precluding the possibility of extensive formation of GaSb.

4.2 Temperature Dependence For electrodepositions performed below $60{ }^{\circ} \mathrm{C}$, the presented data suggest that only GaSb with short range order was produced. The mode emerging at around $150 \mathrm{~cm}^{-1}$ tentatively assigned as the longitudinal acoustic mode [20,22] has an unusually large relative intensity. Accordingly, this feature could separately indicate amorphous $\mathrm{Sb}^{0}[19]$ is produced below this threshold temperature, i.e. the electrodeposited materials are not stoichiometric. The origin of this specific threshold temperature is unclear. We posit that some (or multiple) step(s) in the GaSb crystal growth have activation energies comparable to these temperatures. However, we do not believe this aspect is tantamount to electrodeposition of amorphous GaSb and separate thermal annealing as the route to crystalline GaSb. Experiments performed where GaSb was electrodeposited below the threshold 
temperature and then annealed just above the threshold temperature conclusively showed no increased crystallinity.

The duration of the electrodepositions performed here similarly influenced the apparent crystallinity. The Raman spectra collected at short times suggested the presence of GaSb with only short range order.[19, 22] The disappearance of signatures suggestive of $\mathrm{Sb}^{0}$ and the peak shift of the TO mode both suggest that the GaSb crystallites became more defined throughout the course of the electrodeposition. If correct, these observations support the premise of a dynamic equilibrium within the liquid metal between dissolved GaSb and solid GaSb, emphasizing the value of the metallurgical properties of the liquid metal electrode in ec-LLS.

4.3 Comparing and Contrasting GaSb and GaAs ec-LLS Three main observations were consistent between the ec-LLS processes for GaSb and GaAs. First, the concentration of the dissolved precursor strongly determined whether the electrodeposited film was composed of the target III-V compound or mainly the pure group V element. Second, the crystalline quality of the electrodeposited film was more sensitive to changes in the temperature than to changes in the applied potential. Simply, increasing the overpotential used for ec-LLS did not affect a discernible change in the observable crystallite size. Third, a temperature threshold was apparent, below which only disordered III-V films were observed. These cumulative observations support the general premise that ec-LLS for GaSb and GaAs operates by the scheme outlined in Figure 1. Specifically, crystal nucleation and growth occur after the initial electroreduction is evident and likely not at the electrolyte/liquid metal interface. The exact location where crystal growth initiates and continues cannot be determined from the data collected here. We have previously shown the possibility for heterogeneous crystal nucleation in ec-LLS[31, 32] but that requires that the dimensions of the liquid metal electrode are small enough to ensure transport to a nucleating interface. In both the system presented here and previously for GaAs at bulk liquid Ga pool electrodes, the nucleation and crystal growth likely occurs homogeneously, i.e. within the liquid gallium electrode. The depth from the liquid electrolyte/liquid metal interface into the bulk liquid metal at which this homogeneous nucleation occurs is not presently known.

Despite the similarities, the GaSb ec-LLS process also differs significantly from GaAs ec-LLS. Anecdotally, the formation of a visible film appeared to take longer during GaSb ec-LLS as compared to GaAs ec-LLS. That is, the Ga electrode began to change its visible hue (to yellow) within the first 10 minutes of GaAs ec-LLS[15] while in GaSb ec-LLS the Ga electrode appeared unchanged for up to 30 min. In addition, the data indicated the crystallite size is larger for GaSb than GaAs by factors of $10^{2}-10^{3}$ 
at the same process temperatures. Similarly, the GaSb film thickness is about 15 times larger than what was observed for GaAs electrodeposition lasting $120 \mathrm{~min}$.

An important difference between $\mathrm{Sb}$ and As is the fact that the former is approximately $10^{5}$ times more soluble in Ga than the latter, as determined from the corresponding phase diagrams extrapolated to the temperatures explored here.[15, 33-35] The difference in the equilibrium solubility has several consequences. First, the greater solvating power of $\mathrm{Ga}$ towards $\mathrm{Sb}^{0}$ means that a larger absolute concentration is needed to reach supersaturation for GaSb as compared to GaAs. Second, the rate of dissolution into Ga is necessarily different. Specifically, the rate of dissolution of a solute into a solvent is given by eq 1 , [36]

$$
\frac{\partial C}{\partial t}=\frac{D S\left(C_{e}-C\right)}{V h}
$$

where $\partial C / \partial t$ is the dissolution rate, $D$ is the diffusion coefficient of the solute, $S$ is the surface area of the solid in contact with the solvent, $V$ is the volume of the dissolving medium, $h$ is the height or thickness of the boundary layer (between the solid $\mathrm{Sb}^{0}$ and the bulk liquid Ga pool), $C_{e}$ is the equilibrium solubility of the solute in the solvent, and $C$ is the concentration of the solute at a specific location and time. Even when the electroreduction rates of the oxidized precursor yields similar surface concentrations and shapes/densities of $\mathrm{As}^{0}$ and $\mathrm{Sb}^{0}$ at the electrolyte/Ga interface, the rate of $\mathrm{Sb}^{0}$ dissolution should be inherently faster as compared to the rate for $\mathrm{As}^{0}$ by virtue of the value of $C_{\mathrm{e}}$ (assuming $D$ is the same). This aspect correspondingly implies the $\mathrm{Sb}^{0}$ concentration gradient as a function of distance (i.e. from the surface to the interior of $\mathrm{Ga}$ ) will be smaller than the concentration gradient for $\mathrm{As}^{0}$ since the latter won't diffuse as far before undergoing homogeneous nucleation. Simply, $\mathrm{Sb}^{0}$ ought to diffuse to a greater depth within the liquid metal. The combination of both the larger absolute concentration needed to reach supersaturation as well as the faster dissolution rate could potentially lead to the longer time it took to optically observe the film. However, following nucleation, the crystal growth rate is a function of the absolute solute concentration,[35] where crystals grow faster and larger in solutions with a higher concentration of solute. The fact that the GaSb crystals and resultant films are larger and thicker than those observed for GaAs ec-LLS is in accord with this perspective.

These discrepancies between the deposition of GaSb and GaAs further bolster the claim that ecLLS is a hybrid deposition process (electrodeposition + solution-based crystal growth). That is, the electrochemical driving force for electrocrystallization (the overpotential) has only an indirect effect on crystallinity but factors that affect supersaturation (the driving force for solution-based crystal growth) within Ga have a profound effect on the resultant quality and yield of the deposit. Nevertheless, a more 
descriptive and quantitative model of crystal nucleation/growth in ec-LLS is still needed to rationalize the particular differences in nucleation rates and total film thicknesses. Such work is ongoing in our lab.

\section{Conclusions.}

Crystalline GaSb was electrodeposited through ec-LLS under mild process conditions. X-ray diffraction, electron microscopy, electron diffraction, and Raman spectroscopy illustrated the electrodeposited material was crystalline $\mathrm{GaSb}$ at $T \geq 60{ }^{\circ} \mathrm{C}$ and at formal concentrations of $\mathrm{Sb}_{2} \mathrm{O}_{3}$ below $0.1 \mathrm{mM}$ and applied potentials more negative than $-1.26 \mathrm{~V}$ vs Ag/AgCl. The collected Raman spectra implicated $\mathrm{Sb}^{0}$ and disordered $\mathrm{GaSb}$ as the major and minor products outside of these conditions. The presented analysis illustrated that temperature and electrodeposition time were the only factors that strongly affected the apparent crystallite size. In this way, the general features of the GaSb ec-LLS process followed the features for GaAs ec-LLS under the same conditions. However, clear differences in the crystals produced suggest that the metallurgical properties of the solute-liquid metal pairing have a significant impact on the nature of the resultant semiconductor crystals.

Acknowledgements. Acknowledgement is made to the Camille Dreyfus Teacher Scholar Award and the National Science Foundation (1505635) for support of this research. J.D. and L.M. separately recognize the Rackham Research Award. The JEOL 3011 TEM and the FEI Nova Nanolab SEM instruments used in this work are maintained through the University of Michigan Electron Microbeam Analysis Laboratory through the NSF support (DMR-0315633 and DMR-0320740, respectively). In addition, Dr. Kai Sun and Mr. Roy Wentz are thanked for informative transmission electron microscopy discussions and specialty glass work, respectively.

Supporting Information. A full description of the experimental methods and characterizations including a Tafel plot for $\mathrm{Ga}(l)$ electrode towards the $\mathrm{H}^{+}(\mathrm{aq}) / \mathrm{H}_{2}(g)$ couple, Raman spectra and time lapse photographs of Galvanic reduction experiments as well as energy dispersive X-ray fluorescence spectra. The material is available free of charge via the internet. 


\section{References.}

[1] G. Mattarolo, Development and Modelling of a Thermophotovoltaic System, Kassel University Press2007.

[2] C.A. Wang, H.K. Choi, S.L. Ransom, G.W. Charache, L.R. Danielson, D.M. DePoy, Highquantum-efficiency $0.5 \mathrm{eV}$ GaInAsSb/GaSb thermophotovoltaic devices, Applied Physics Letters, 75 (1999) 1305-1307.

[3] B.-C. Juang, R.B. Laghumavarapu, B.J. Foggo, P.J. Simmonds, A. Lin, B. Liang, D.L. Huffaker, GaSb thermophotovoltaic cells grown on GaAs by molecular beam epitaxy using interfacial misfit arrays, Applied Physics Letters, 106 (2015) 111101.

[4] A.G. Milnes, A.Y. Polyakov, Gallium antimonide device related properties, Solid-State Electronics, 36 (1993) 803-818.

[5] P.S. Dutta, K.S. Sangunni, H.L. Bhat, V. Kumar, Experimental determination of melt-solid interface shapes and actual growth rates of gallium antimonide grown by vertical Bridgman method, Journal of Crystal Growth, 141 (1994) 476-478.

[6] L.M. Fraas, G.R. Girard, J.E. Avery, B.A. Arau, V.S. Sundaram, A.G. Thompson, J.M. Gee, GaSb booster cells for over 30\% efficient solar-cell stacks, Journal of Applied Physics, 66 (1989) 3866-3870.

[7] G. Motosugi, T. Kagawa, Temperature Dependence of the Threshold Current of AlGaAsSb/GaSb DH Lasers, Japanese Journal of Applied Physics, 19 (1980) 2303.

[8] P. Capper, M. Mauk, L. Wiley Online, Liquid phase epitaxy of electronic, optical, and optoelectronic materials, Wiley, Chichester, England ; Hoboken, NJ, 2007.

[9] F. Paolucci, G. Mengoli, M.M. Musiani, An electrochemical route to GaSb thin films, J Appl Electrochem, 20 (1990) 868-873.

[10] J.J. McChesney, J. Haigh, I.M. Dharmadasa, D.J. Mowthorpe, Electrochemical growth of $\mathrm{GaSb}$ and InSb for applications in infra-red detectors and optical communication systems, Optical Materials, 6 (1996) 63-67.

[11] B. Sopori, Impurities and defects in photovoltaic Si devices: a review, Proceedings-SPIE the International Society for Optical Engineering, International Society for Optical Engineering; 1999, 2000, pp. 1214-1226.

[12] U.K. Mishra, J. Singh, SpringerLink, Semiconductor Device Physics and Design, Springer, Dordrecht, 2007.

[13] A.I. Carim, S.M. Collins, J.M. Foley, S. Maldonado, Benchtop Electrochemical LiquidLiquid-Solid Growth of Nanostructured Crystalline Germanium, Journal of the American Chemical Society, 133 (2011) 13292-13295.

[14] J. Gu, E. Fahrenkrug, S. Maldonado, Direct Electrodeposition of Crystalline Silicon at Low Temperatures, Journal of the American Chemical Society, 135 (2013) 1684-1687.

[15] E. Fahrenkrug, J. Gu, S. Maldonado, Electrodeposition of Crystalline GaAs on Liquid Gallium Electrodes in Aqueous Electrolytes, Journal of the American Chemical Society, 135 (2013) 330-339.

[16] A.J. Bard, R. Parsons, J. Jordan, P. International Union of, C. Applied, Standard potentials in aqueous solution, M. Dekker, New York, 1985.

[17] M. Pourbaix, Atlas of electrochemical equilibria in aqueous solutions, Pergamon Press, Oxford, New York, 1966.

[18] X. Wang, K. Kunc, I. Loa, U. Schwarz, K. Syassen, Effect of pressure on the Raman modes of antimony, Physical Review B, 74 (2006) 134305.

[19] J.B. Renucci, W. Richter, M. Cardona, E. SchÖstherr, Resonance raman scattering in group Vb semimetals: As, Sb, and Bi, physica status solidi (b), 60 (1973) 299-308. 
[20] R. Ferrini, M. Galli, G. Guizzetti, M. Patrini, A. Bosacchi, S. Franchi, R. Magnanini, Phonon response of $\mathrm{Al}_{\mathrm{x}} \mathrm{Ga}_{1-\mathrm{x}} \mathrm{Sb} / \mathrm{GaSb}$ epitaxial layers by Fourier-transform infrared-reflectance and Raman spectroscopies, Physical Review B, 56 (1997) 7549-7553.

[21] P.B. Klein, R.K. Chang, Comparison of second-order Raman scattering measurements with a phonon density-of-states calculation in GaSb, Physical Review B, 14 (1976) 2498-2502.

[22] S.V. Demishev, Y.V. Kosichkin, A.G. Lyapin, N.N. Melnik, Raman Light-Scattering In Amorphous Gallium Antimonide, Žurnal èksperimental'noj i teoretičeskoj fiziki, 104 (1993) 2881-2893.

[23] Gallium antimonide (GaSb), phonon dispersion, phonon frequencies, in: O. Madelung, U. Rössler, M. Schulz (Eds.) Group IV Elements, IV-IV and III-V Compounds. Part b - Electronic, Transport, Optical and Other Properties, Springer Berlin Heidelberg2002, pp. 1-5.

[24] D.N. Astrov, N.A. Razhba, Y.E. Razhba, Triple point and melting point of gallium, Meas Tech, 30 (1987) 247-250.

[25] S. Winnerl, S. Sinning, T. Dekorsy, M. Helm, Increased terahertz emission from thermally treated GaSb, Applied Physics Letters, 85 (2004) 3092-3094.

[26] M. Birkholz, P.F. Fewster, C. Genzel, L. Wiley Online, Thin film analysis by X-ray scattering, Wiley-VCH, Weinheim, 2006.

[27] D.B. Williams, C.B. Carter, SpringerLink, Transmission Electron Microscopy A Textbook for Materials Science, Springer US, Boston, MA, 2009.

[28] R. Brebrick, The liquidus line and gibbs free energy of formation of a crystalline compound AmBn(c). II. Analysis of the liquidus lines of InSb, InAs, GaSb, and GaAs, Metall and Materi Trans B, 2 (1971) 3377-3383.

[29] L. Guo, P.C. Searson, On the influence of the nucleation overpotential on island growth in electrodeposition, Electrochimica Acta, 55 (2010) 4086-4091.

[30] A.J. Bard, L.R. Faulkner, Electrochemical methods: fundamentals and applications, Wiley, New York, 2001.

[31] E. Fahrenkrug, J. Gu, S. Jeon, P.A. Veneman, R.S. Goldman, S. Maldonado, RoomTemperature Epitaxial Electrodeposition of Single-Crystalline Germanium Nanowires at the Wafer Scale from an Aqueous Solution, Nano Letters, 14 (2014) 847-852.

[32] L. Ma, J. Gu, E. Fahrenkrug, S. Maldonado, Electrochemical Liquid-Liquid-Solid Deposition of Crystalline Ge Nanowires as a Function of Ga Nanodroplet Size, Journal of The Electrochemical Society, 161 (2014) D3044-D3050.

[33] M. Hansen, K. Anderko, I.I.T.R. Institute, Constitution of binary alloys, McGraw-Hill, New York, 1958.

[34] T.L. Ngai, R.C. Sharma, Y.A. Chang, The Ga-Sb (Gallium-Antimony) system, Bulletin of Alloy Phase Diagrams, 9 (1988) 586-591.

[35] C.D. Thurmond, Phase equilibria in the GaAs and the GaP systems, Journal of Physics and Chemistry of Solids, 26 (1965) 785-802.

[36] A. Dokoumetzidis, P. Macheras, A century of dissolution research: From Noyes and Whitney to the Biopharmaceutics Classification System, International Journal of Pharmaceutics, 321 (2006) 1-11.

\section{Figures.}




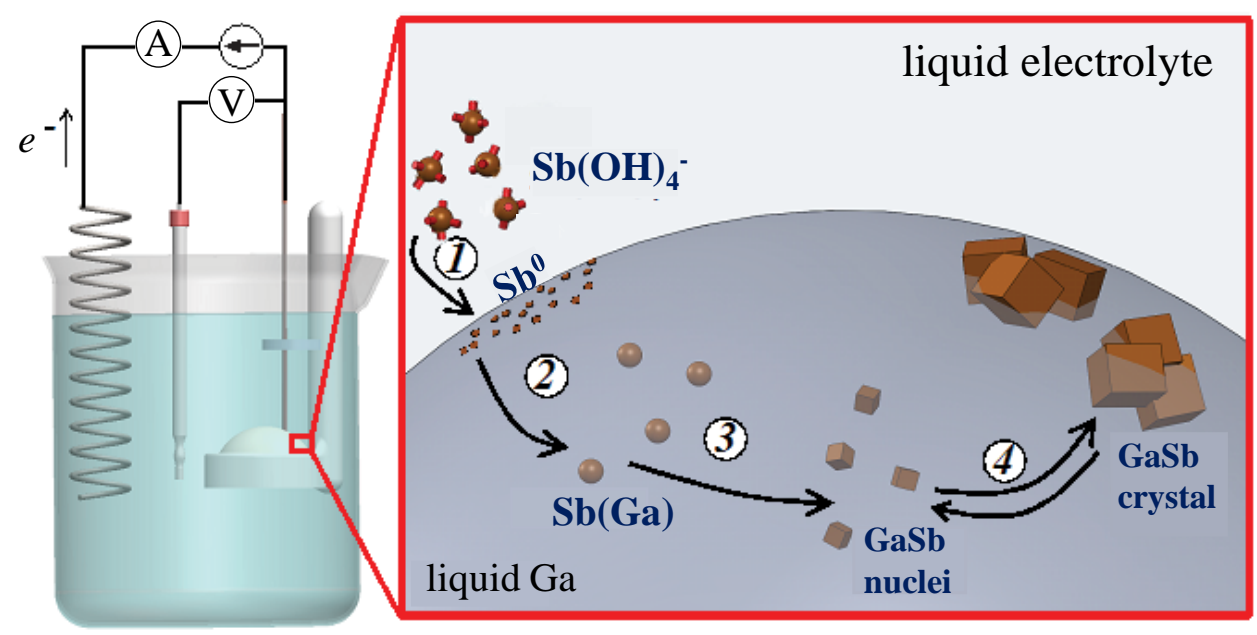

Figure 1. Schematic depiction of GaSb ec-LLS. (1) The dissolved $\mathrm{Sb}_{2} \mathrm{O}_{3}(\mathrm{aq})$ precursor is electroreduced to $\mathrm{Sb}^{0}$. (2) Dissolution of $\mathrm{Sb}^{0}$ into the pool of $\mathrm{Ga}(\mathrm{l})$ and subsequent metallurgical alloying reaction with the liquid metal. (3) Supersaturation within the liquid metal phase leads to the formation of GaSb nuclei. (4) GaSb crystals grow and emerge from the liquid Ga pool. 

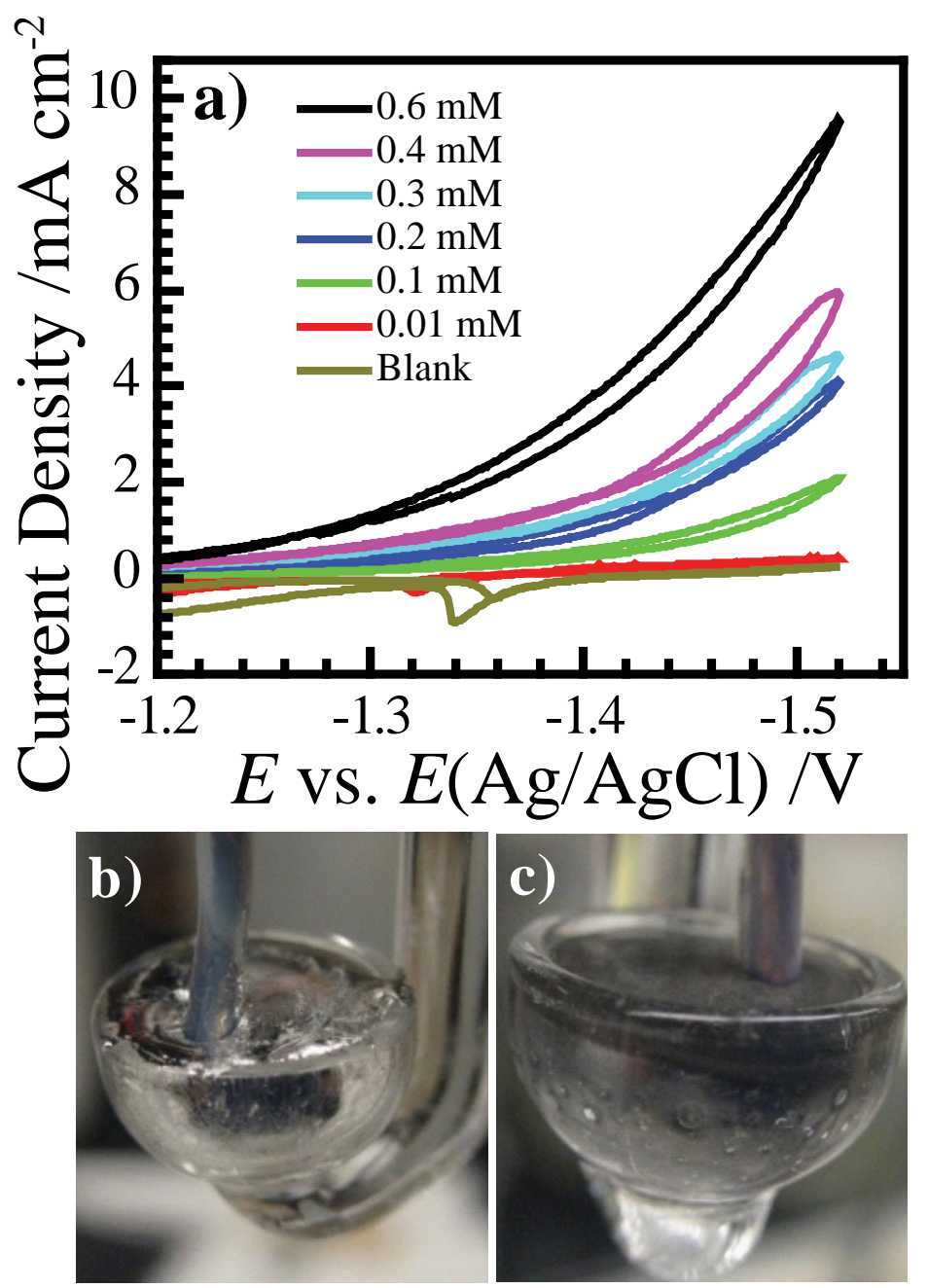

Figure 2. a) Voltammetric responses for a $\mathrm{Ga}(\mathrm{l})$ working electrode in an aqueous electrolyte containing $0.6 \mathrm{M}$ $\mathrm{NaOH}$ with and without dissolved $\mathrm{Sb}_{2} \mathrm{O}_{3}(\mathrm{aq})$ at various formal concentrations up to the solubility limit at $25{ }^{\circ} \mathrm{C}$ with a scan rate of $10 \mathrm{mV} / \mathrm{s}$. b,c) Optical photograph of a clean $\mathrm{Ga}(l)$ pool working electrode with a geometric surface area of $0.615 \mathrm{~cm}^{2}$ housed in a glass bowl $\left(V=350 \mathrm{~cm}^{3}\right)$ before (b) and after (c) applying $E=-1.47 \mathrm{~V} \mathrm{vs} \mathrm{Ag/AgCl} \mathrm{for}$ 1 hour while submerged in an aqueous electrolyte containing $0.1 \mathrm{mM} \mathrm{Sb}_{2} \mathrm{O}_{3}$ and $0.6 \mathrm{M} \mathrm{NaOH}$. Electrical contact was made through a top Pt wire insulated from the electrolyte by polytetrafluoroethylene. 


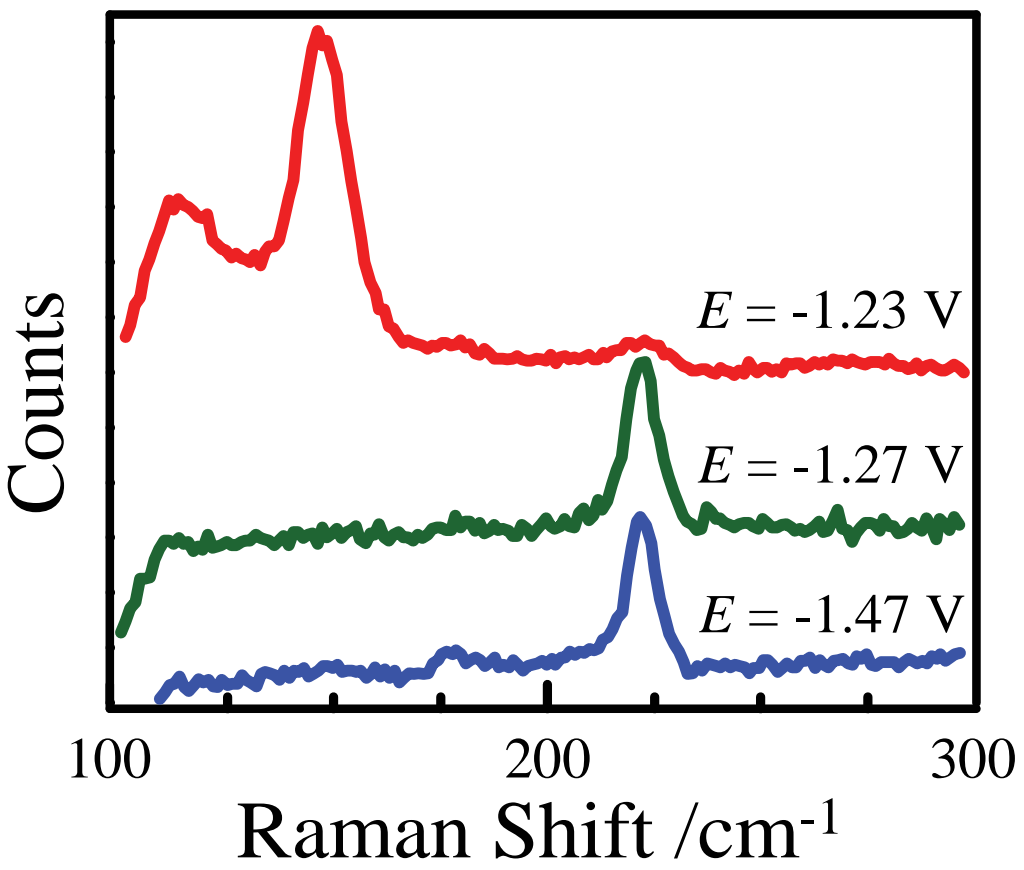

Figure 3. Normalized Raman spectra for films deposited on $\mathrm{Ga}(\mathrm{l})$ after being immersed in aqueous $0.6 \mathrm{M} \mathrm{NaOH}$ with $\mathrm{Sb}_{2} \mathrm{O}_{3}$ dissolved at a formal concentration of $0.1 \mathrm{mM}$ while being held at a constant applied potential for $60 \mathrm{~min}$ at $T=90^{\circ} \mathrm{C}$. Spectra are offset vertically for clarity. 


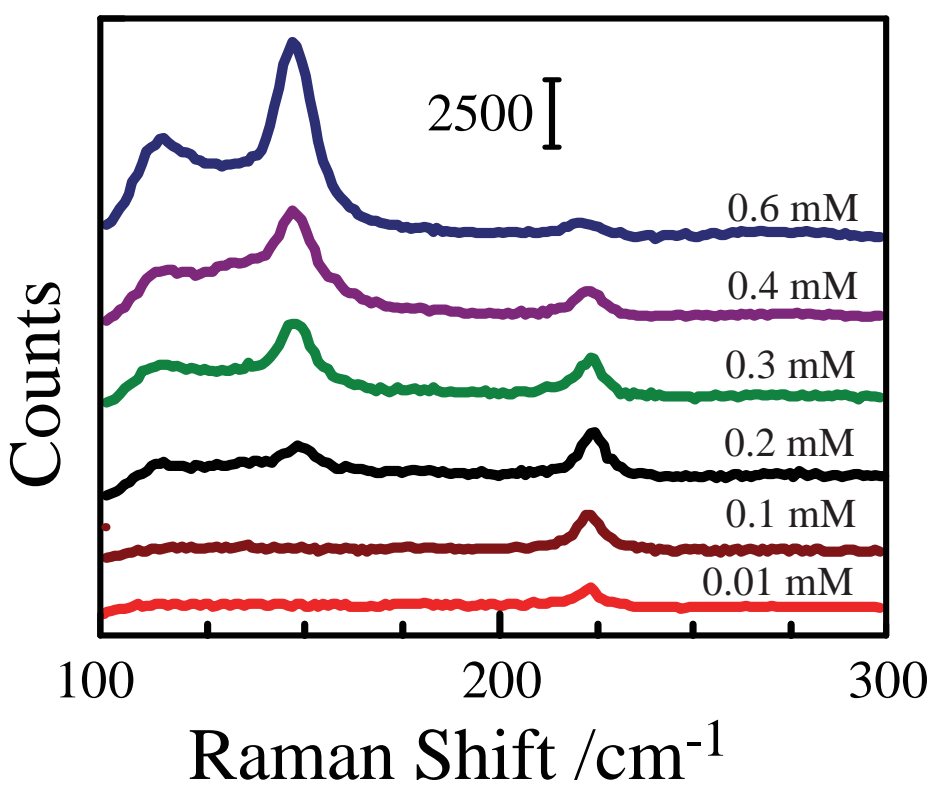

Figure 4. Raman spectra of films deposited on the $\mathrm{Ga}(\mathrm{l})$ electrode submerged in an aqueous electrolyte of $0.6 \mathrm{M}$ $\mathrm{NaOH}$ with several different concentrations of the $\mathrm{Sb}_{2} \mathrm{O}_{3}$ precursor and held at $E=-1.47 \mathrm{~V}$ for $60 \mathrm{~min}$ at $T=90{ }^{\circ} \mathrm{C}$. Spectra are offset vertically for clarity. 

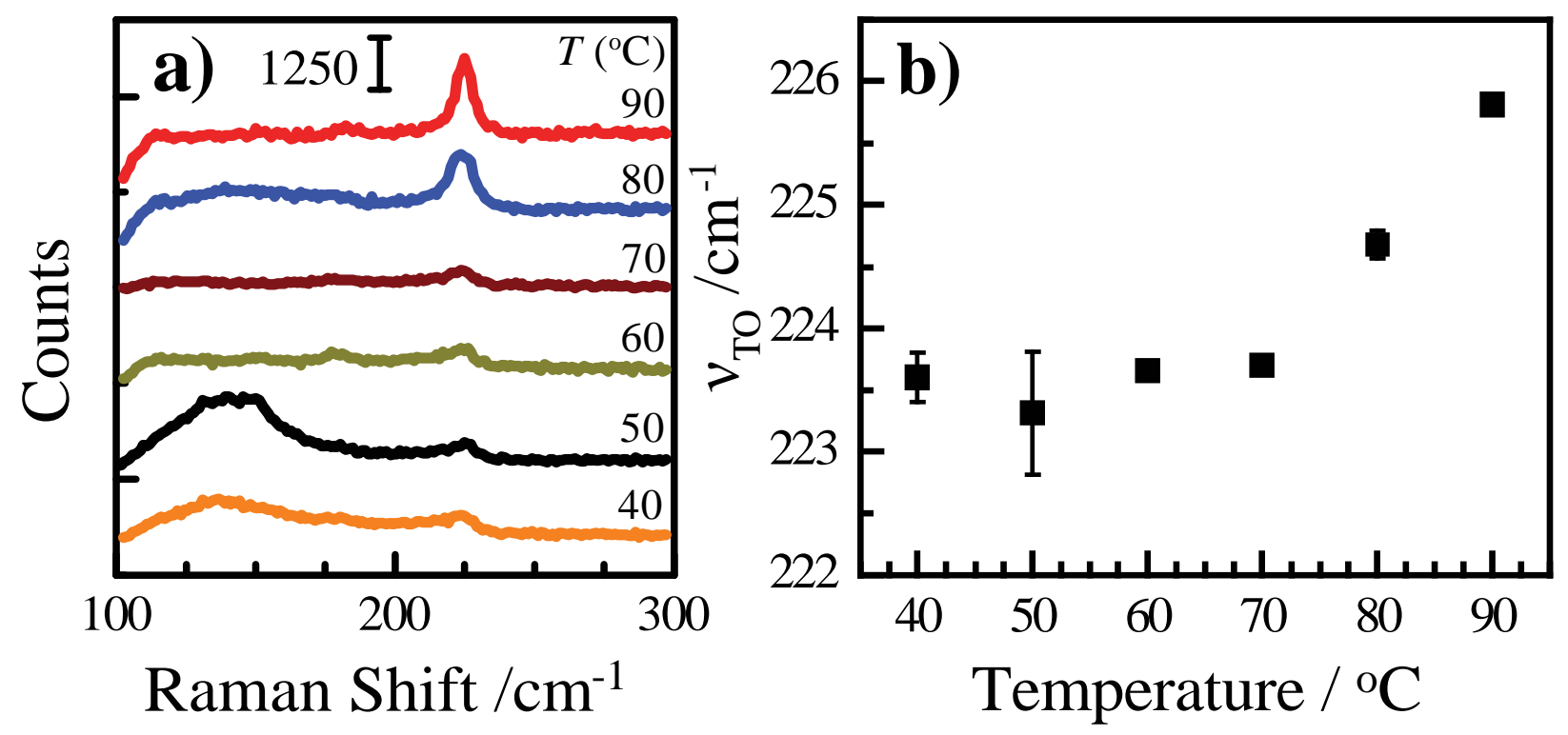

Figure 5. (a) Raman spectra of GaSb films deposited on a $\mathrm{Ga}(\mathrm{l})$ pool electrode with each trace corresponding to a different temperature used in the deposition. The $\mathrm{Ga}(\mathrm{l})$ was held at a constant potential of $-1.47 \mathrm{~V}$ in $0.6 \mathrm{M} \mathrm{NaOH}$ with dissolved $\mathrm{Sb}_{2} \mathrm{O}_{3}$ at a formal concentration of $0.1 \mathrm{mM}$ for $60 \mathrm{~min}$. Spectra are offset vertically for clarity. (b) The observed Raman shift of the TO phonon mode of bulk crystalline GaSb (v) vs the growth temperature of each deposition. Error bars represent the standard deviation for $N=3$. 


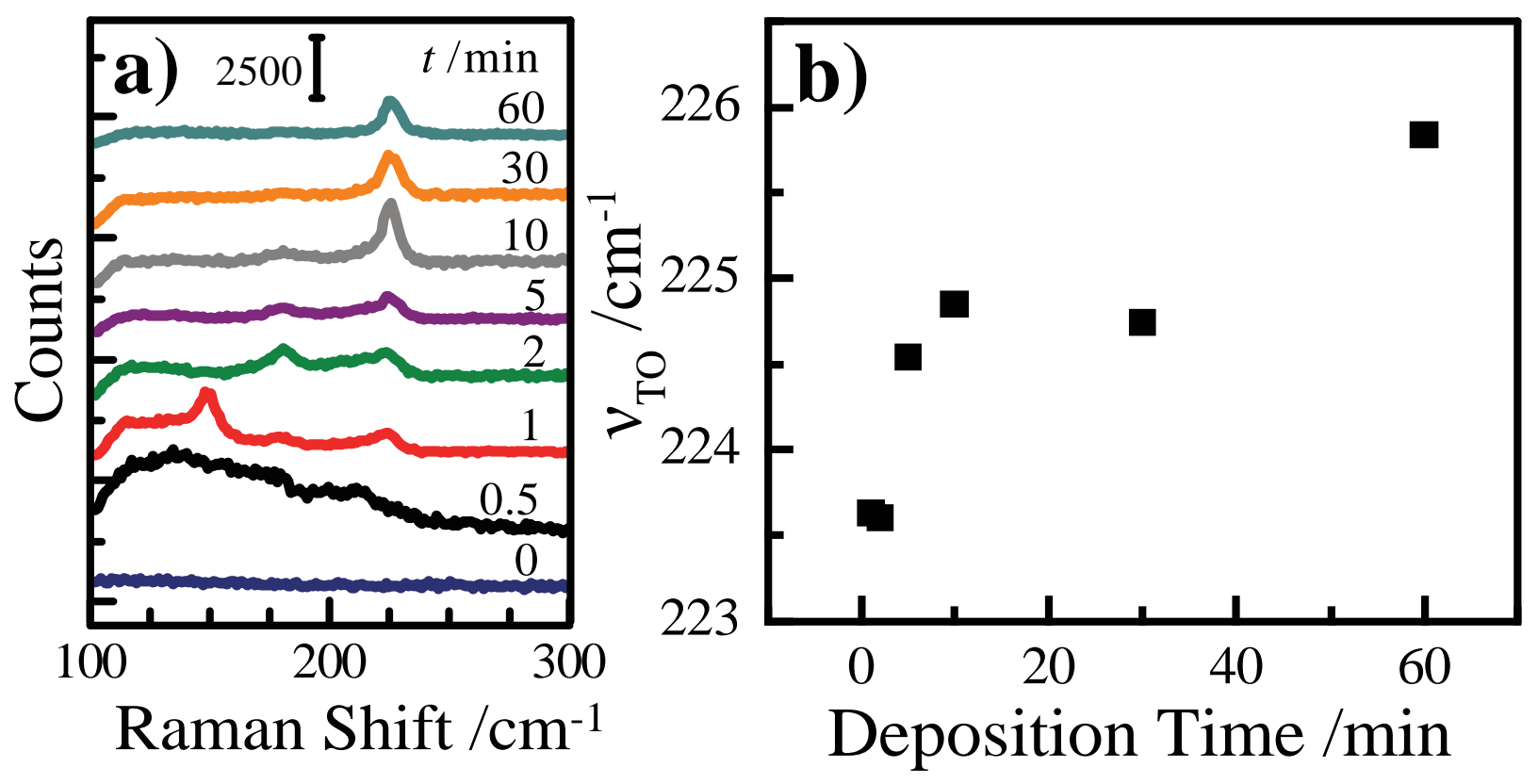

Figure 6. (a) Time-dependent Raman spectra of films deposited at a $\mathrm{Ga}(\mathrm{l})$ electrode at $E=-1.47 \mathrm{~V}$ in aqueous $0.6 \mathrm{M}$ $\mathrm{NaOH}$ with dissolved $\mathrm{Sb}_{2} \mathrm{O}_{3}$ at a formal concentration of $0.1 \mathrm{mM}$ at $T=90{ }^{\circ} \mathrm{C}$ for the indicated deposition time. The intensity of the traces corresponding to the 0 and 0.5 min depositions have been multiplied by a factor of 5 and all of the spectra are offset for clarity. (b) Raman shift of the TO phonon mode of c-GaSb versus the deposition time. 

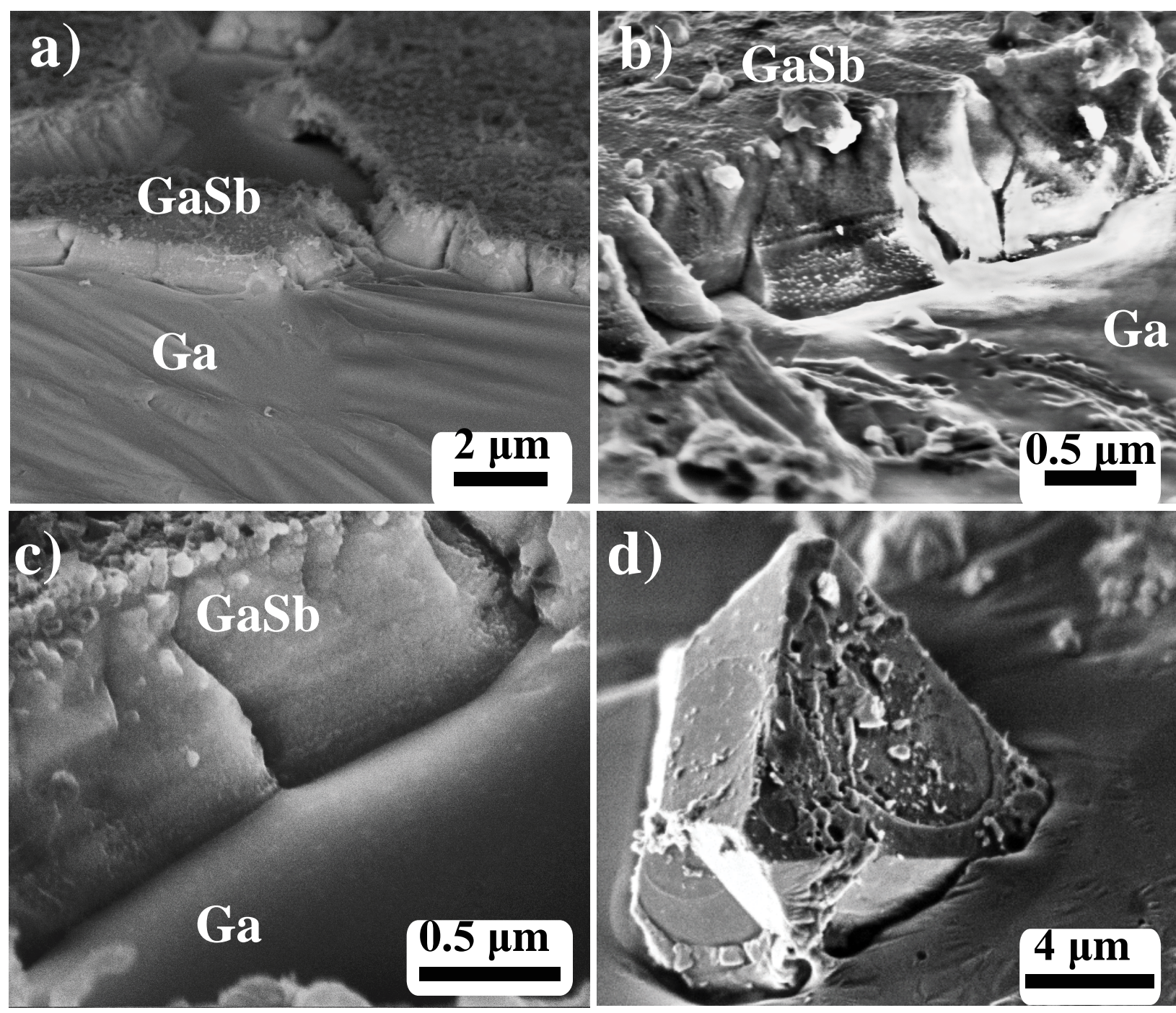

Figure 7. Scanning electron micrographs of films deposited on a $\mathrm{Ga}(\mathrm{l})$ pool electrode submerged in an aqueous 0.6 $\mathrm{M} \mathrm{NaOH}$ with $\mathrm{Sb}_{2} \mathrm{O}_{3}$ dissolved at a formal concentration of $0.1 \mathrm{mM}$ and held at $E=-1.47 \mathrm{~V}$ for $1 \mathrm{hr}$. (a-c) Shows cross sectional images of the visible portions of undisturbed films approximately $1 \mu \mathrm{m}$ above the liquid metal surface. (d) An individual GaSb grain after removal from the liquid metal electrode. 


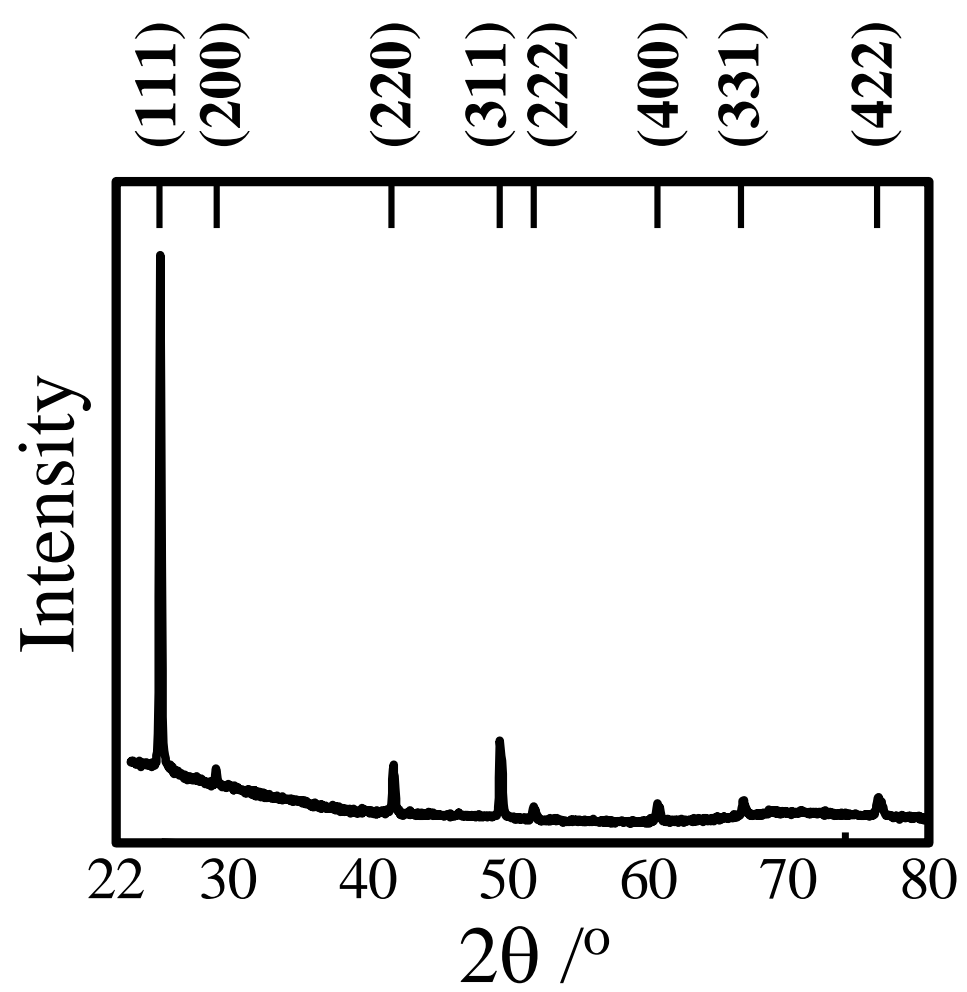

Figure 8. Representative Powder X-ray diffractogram collected from a film deposited on a $\mathrm{Ga}(\mathrm{l})$ pool electrode after being submerged in an electrolyte containing $0.1 \mathrm{mM} \mathrm{Sb}_{2} \mathrm{O}_{3}$ and $0.6 \mathrm{M} \mathrm{NaOH}$ at $90^{\circ} \mathrm{C}$ while held at a constant potential of $-1.47 \mathrm{~V}$ for $60 \mathrm{~min}$. The $2 \theta$ values for the expected crystallographic planes of zinc blende GaSb are denoted at the top. 

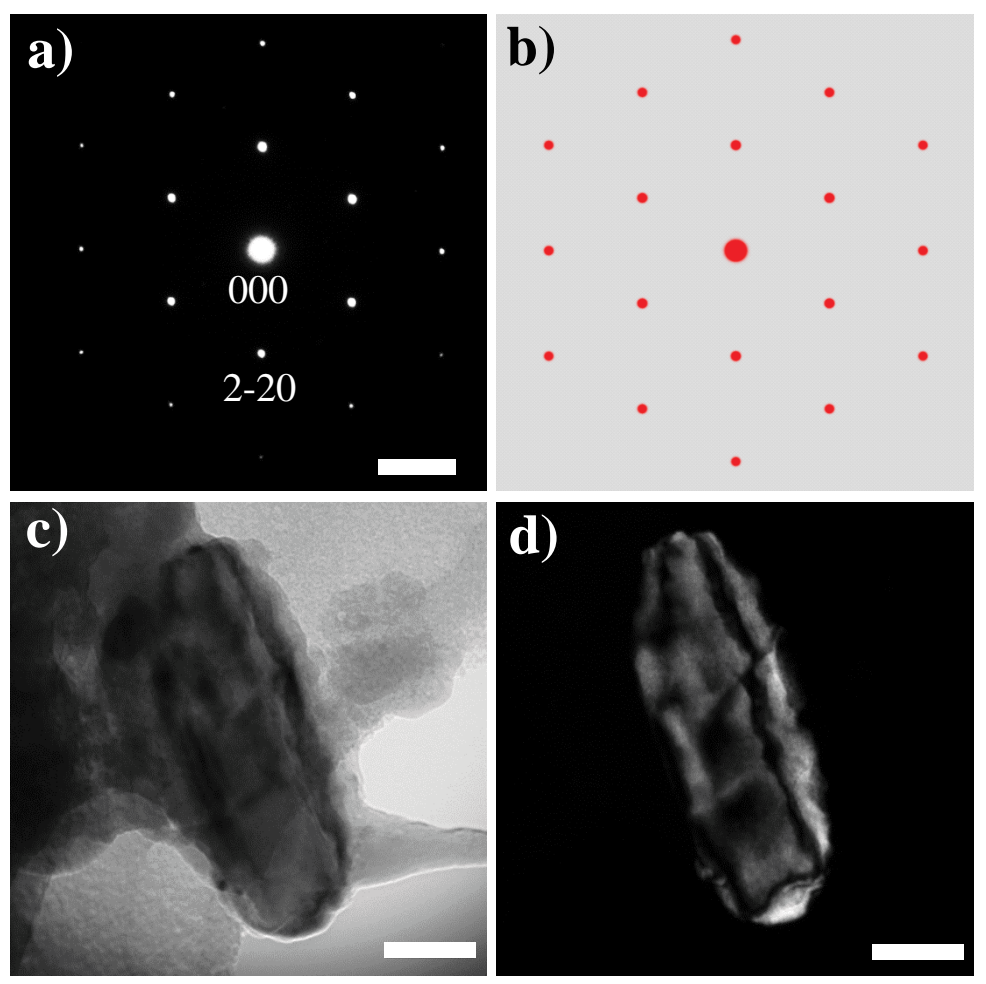

Figure 9. (a-d) Transmission electron micrographs and selected area diffraction patterns of GaSb crystallites prepared under conditions as described in Figure 8. The (a) experimental and (b) modeled electron diffraction patterns observed along the [111] zone axis of a GaSb crystallite. (c) A dark field transmission electron micrograph formed by selecting for the 2-20 diffracted beam. (d) The complementary two-beam bright field comprised of the 000 and 2-20 beams. Scale bars $=$ (a) $0.4 \AA^{-1}$, (c and d) $40 \mathrm{~nm}$. 


\section{High nucleation density}

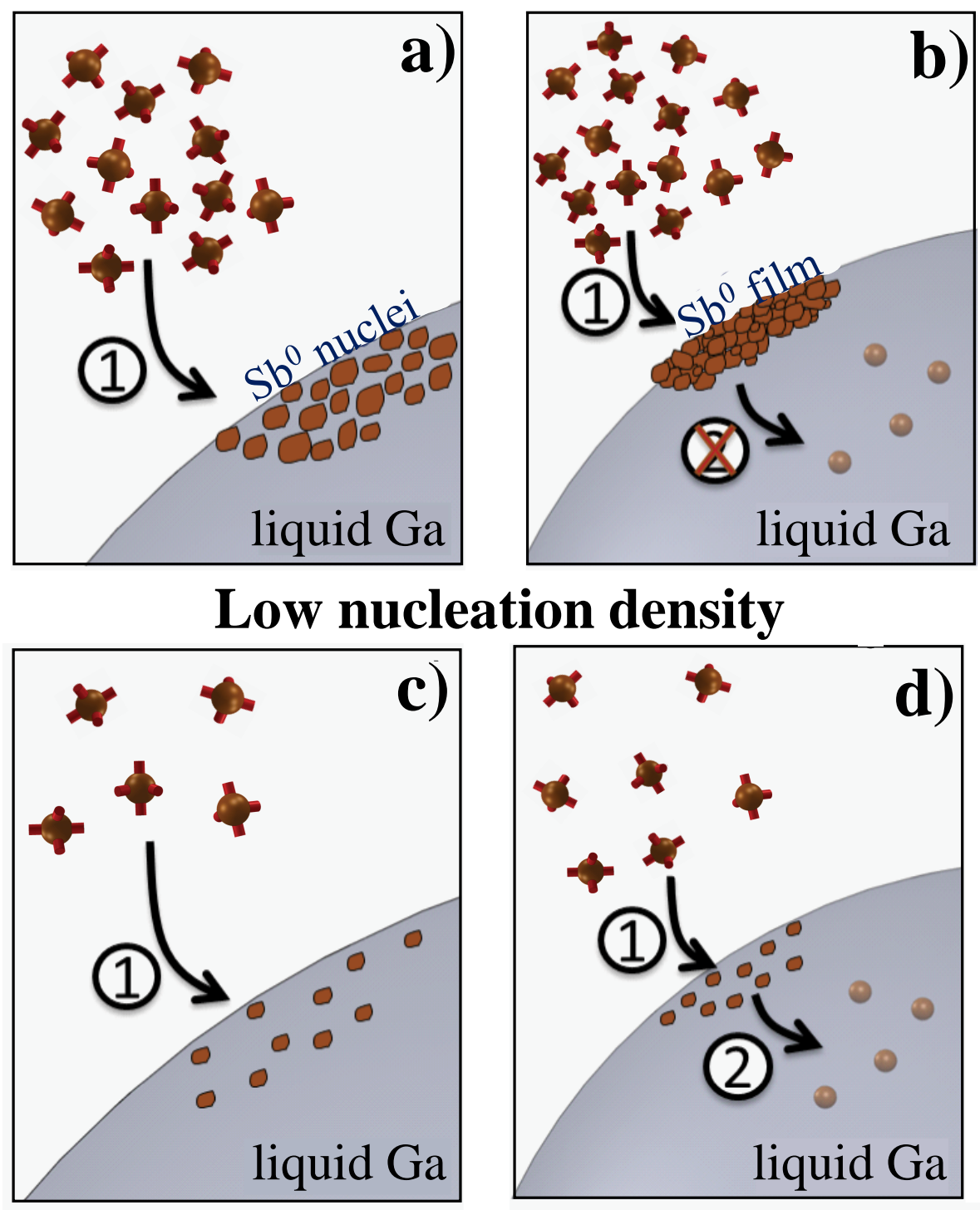

Figure 10. Schematic depiction of the first step and second steps in the proposed scheme for ec-LLS as influenced by conditions that favor high densities and low densities of electrodeposited $\mathrm{Sb}^{0}$ nuclei. 
Tables.

\begin{tabular}{|c|c|c|c|c|}
\hline $\begin{array}{c}\left.\mathrm{Sb}_{2} \mathrm{O}_{3}\right]^{\mathrm{a}} \\
/ \mathbf{m M}\end{array}$ & $\begin{array}{c}\text { Peak Position } \\
\mathrm{cm}^{-1}\end{array}$ & $\begin{array}{c}\text { FWHM } \\
/ \mathbf{c m}^{-1}\end{array}$ & $\begin{array}{c}\text { Relative } \\
\text { Intensity }^{\mathbf{b}}\end{array}$ & Assignment \\
\hline \multicolumn{5}{|l|}{0.01} \\
\hline & 225.8 & 6.24 & 1 & GaSb TO \\
\hline \multicolumn{5}{|l|}{0.1} \\
\hline & 225.8 & 8.16 & 1 & GaSb TO \\
\hline \multicolumn{5}{|l|}{0.2} \\
\hline & 116.3 & 13.29 & 0.27 & $\mathrm{Sb}^{0} \mathrm{Eg}$ \\
\hline & 150.1 & 11.09 & 1.35 & $\mathrm{Sb}^{0} \mathrm{~A} 1 \mathrm{~g}$ \\
\hline & 225.8 & 6.83 & 1 & GaSb TO \\
\hline \multicolumn{5}{|l|}{0.3} \\
\hline & 118.6 & 18.43 & 1.13 & $\mathrm{Sb}^{0} \mathrm{Eg}$ \\
\hline & 151.2 & 11.36 & 3.26 & $\mathrm{Sb}^{0} \mathrm{~A} 1 \mathrm{~g}$ \\
\hline & 225.8 & 7.06 & 1 & GaSb TO \\
\hline \multicolumn{5}{|l|}{0.4} \\
\hline & 119.7 & 12.87 & 2.10 & $\mathrm{Sb}^{0} \mathrm{Eg}$ \\
\hline & 150.1 & 16.85 & 8.55 & $\mathrm{Sb}^{0} \mathrm{~A} 1 \mathrm{~g}$ \\
\hline & 225.8 & 8.33 & 1 & GaSb TO \\
\hline \multicolumn{5}{|l|}{0.6} \\
\hline & 117.5 & 21.42 & 14.48 & $\mathrm{Sb}^{0} \mathrm{Eg}$ \\
\hline & 150.1 & 12.64 & 25.68 & $\mathrm{Sb}^{0} \mathrm{~A} 1 \mathrm{~g}$ \\
\hline & 222.5 & 10.01 & 1 & GaSb TO \\
\hline
\end{tabular}

a. formal concentration of $\mathrm{Sb}_{2} \mathrm{O}_{3}$ dissolved in aqueous solution

b. relative to signal at $225 \mathrm{~cm}^{-1}$ 